\title{
Micro-endoscopic ear anatomy of guinea pig applied to experimental surgery ${ }^{1}$
}

\author{
Bruno Borges de Carvalho Barros ${ }^{\mathrm{I}}$, José Santos Cruz de Andrade ${ }^{\mathrm{II}}$, Leandro Borborema Garcia ${ }^{\mathrm{I}}$, Gustavo Ribeiro Pifaia ${ }^{\mathrm{III}}$, \\ Oswaldo Laércio Mendonça Cruz ${ }^{\mathrm{IV}}$, Ektor Tsuneo Onishiv, Norma de Oliveira Penido ${ }^{\mathrm{VI}}$
}

DOI: http://dx.doi.org/10.1590/S0102-86502014001300002

IFellow Master degree - Otolaryngology and Head and Neck Surgery Division - Federal University of São Paulo. Surgical procedures, acquisition of data, manuscript writing.

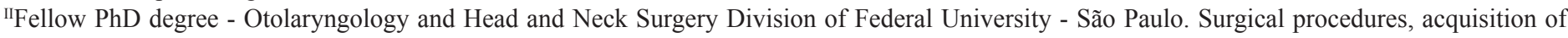
data, manuscript writing.

IIIOtology Fellowship Specialization - Otolaryngology and Head and Neck Surgery Division - Federal University of São Paulo. Surgical procedures, acquisition of data.

${ }^{\text {IV }} \mathrm{PhD}$, Associate Professor - Otolaryngology and Head and Neck Surgery Division - Federal University of São Paulo. Interpretation of data, critical revision.

${ }^{\mathrm{v}} \mathrm{PhD}$, Affiliated Professor - Otolaryngology and Head and Neck Surgery Division - Federal University - São Paulo. Conception and design of the study, critical revision.

${ }^{{ }^{V}} \mathrm{PhD}$, Associate Professor - Otolaryngology and Head and Neck Surgery Department - Federal University of São Paulo. Conception and design of the study, critical revision.

\section{ABSTRACT}

PURPOSE: To describe topographic and endoscopic anatomy of guinea pig ear for development of surgical approaches in experimental studies.

METHODS: Experimental study. Eight adult guinea pigs (Cavia porcellus) were used in this study. Four animals were described through endoscopic view and four animals were used to describe topographic anatomy.

RESULTS: The main structures of middle ear were well identified through endoscopy view: oval and round window, ossicles and vascular structures. Temporal bone position, landmarks and its relations to skull are perceived with topographic description.

CONCLUSION: Topographic anatomic description allowed exposition of temporal bone relations for external surgical approaches. Alternatively, grooves and middle ear structures were identified and may be used to transcanal accesses.

Key words: Endoscopy. Anatomy. Guinea pigs. 


\section{Introduction}

Experimental models have primordial importance in the development of Otolaryngology and Otology. Knowledge of the surgical anatomy of hearing and balance organs is crucial for development of studies involving animals ${ }^{1}$.

Guinea pig temporal bone and its structures are very similar to human anatomy. When compared to other animal models, guinea pigs are associated with better surgical access to the ear, mainly due to the size of its bulla mastoidea ${ }^{2}$.

Endoscopes were first employed in otology for anatomic studies. Middle ear was observed through ear canal. They improved exploration of hidden spots and allowed visualization of difficult surgical areas, such as sinus tympani, tegmen tympani and round and oval windows 3 .

There are many descriptions of guinea pigs ear anatomy, but few studies concern about its surgical and endoscopic correlations ${ }^{2,3}$.

Knowledge of topographic and endoscopic ear anatomy may facilitate surgical approaches in experimental studies with guinea pig. The purpose of this study is to describe topographic and endoscopic anatomy of guinea pig ear for development of surgical approaches in experimental studies.

\section{Methods}

This experimental study underwent and was approved by local ethics committee under registration number 0021/09. All procedures were conducted based on ethic rules of experimental surgical techniques committee.

Eight adult guinea pigs (Cavia porcellus) were used in this study. Four animals were described through endoscopic view and four animals were used to describe topographic anatomy. Animals were obtained in local vivarium.

For topographic description animals underwent cervical dislocation and cephalic portions were removed and fixed in formalin $10 \%$. After dried, were boiled in a vat containing hydrogen peroxide at 10 volumes for twenty minutes. Soft tissue was manually removed, leaving only bony structures. Photographic documentation was conducted with aid of a digital camera Canon EOS 50D ® (CANON LATIN AMERICA, INC.), coupled with macro photography objective Macro EF $100 \mathrm{~mm}$ f/2.8L IS USM ® (CANON LATIN AMERICA, INC) and flash Macro Twin Lite MT-24EX ® (CANON LATIN AMERICA, INC.).
For endoscopic description guinea pigs were submitted to intraperitoneal ketamine chloridrate anesthesia $(15 \mathrm{mg} / \mathrm{kg})$ and xilazine chloridrate $(3 \mathrm{mg} / \mathrm{kg})$. With aid of a zero degree $4 \mathrm{~mm}$ endoscope, coupled to a recording camera (GoPro $\left.{ }^{\circledR}\right)$, images of external and middle ear were obtained. Animals were subjected to the following, in the ear studied: retro-auricular incision: held arch incision of about $2.5 \mathrm{~cm}$ initiating adjacent to the pavilion and extending posteriorly. Opening was made in the skin and subcutaneous tissue exposing the fibromuscular layer, which was dissected to identify temporalis muscle. The temporalis muscle was removed superiorly and the posterior auricular vein localized. Drilling allowed identification of structures and landmarks.

\section{Results}

Temporal bone is located posterior to squamosal bone and compounds the ventral half of guinea pig skull. Jugular process is an inferior projection of occipital bone, lateral and posterior to bulla (Figures 1-4). Tympanic bulla is a round aerated cavity, whereas mastoid-like process is an extension without pneumatization. Superiorly squamosal bone forms a process that extends anteriorly composing the zygomatic arch.

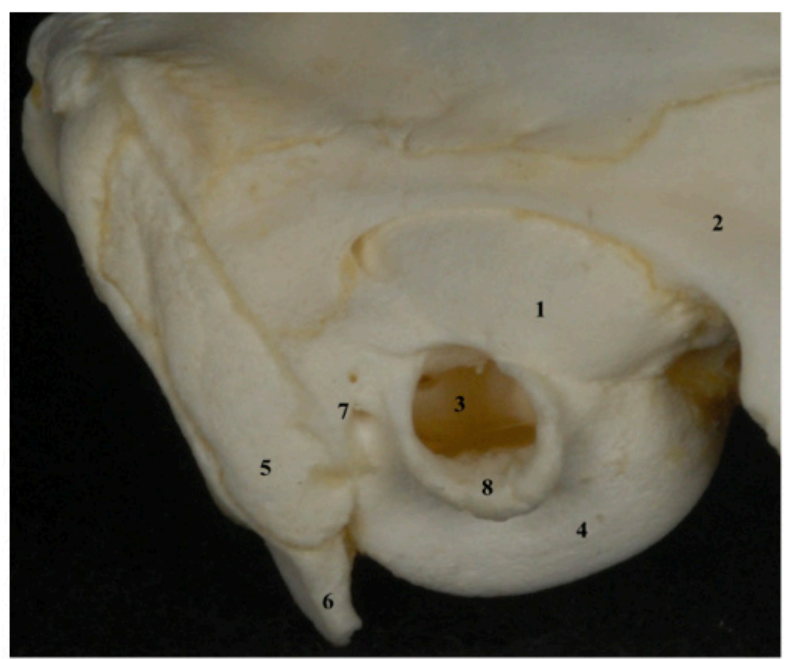

FIGURE 1 - Guinea pig skull, lateral view. 1 - Ventral bula; 2 Zygomatich arch; 3 - Cochlea; 4 - Dorsal; 5 - Mastoid like process; 6 - Para-occipital apophysis; 7 - Facial nerve outer foramen; 8 - External auditory canal. 


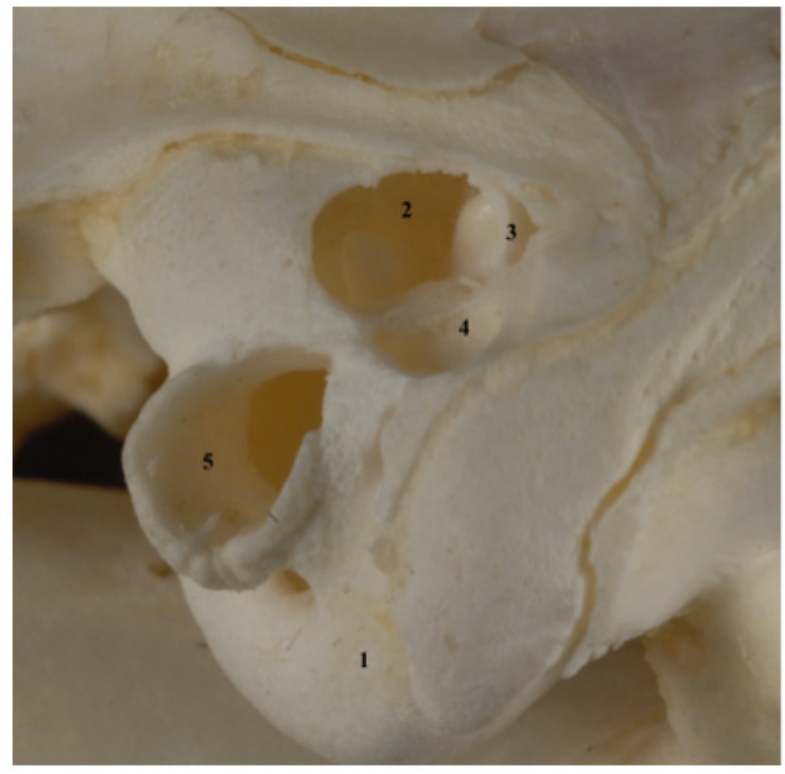

FIGURE 2 - Lateral view, oppened dorsal bula. 1 - Ventral bula; 2 Dorsal bula; 3 - Anterior semicircular canal; 4 - Lateral semicircular canal; 5 - External auditory canal.

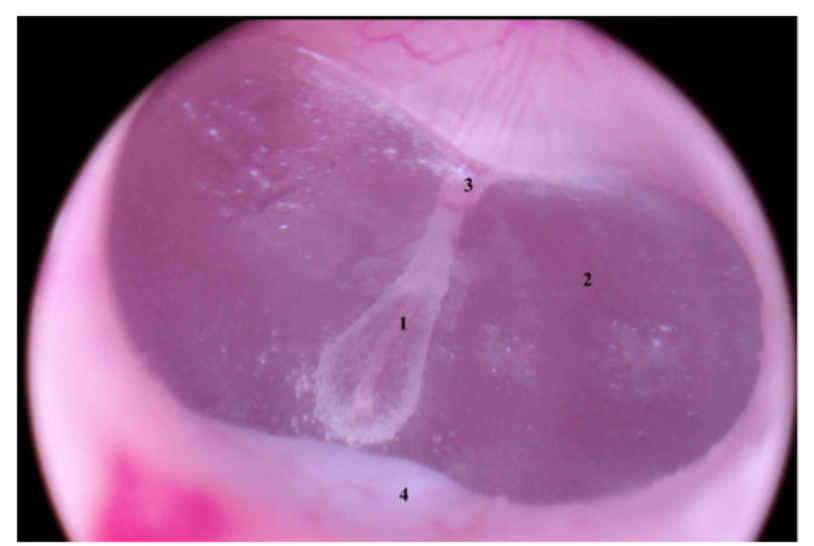

FIGURE 3 - Endoscopic view, through external auditory canal. 1 Malleus handle; 2 - Tympanic membrane; 3 -Malleus (neck); 4 -External auditory canal.

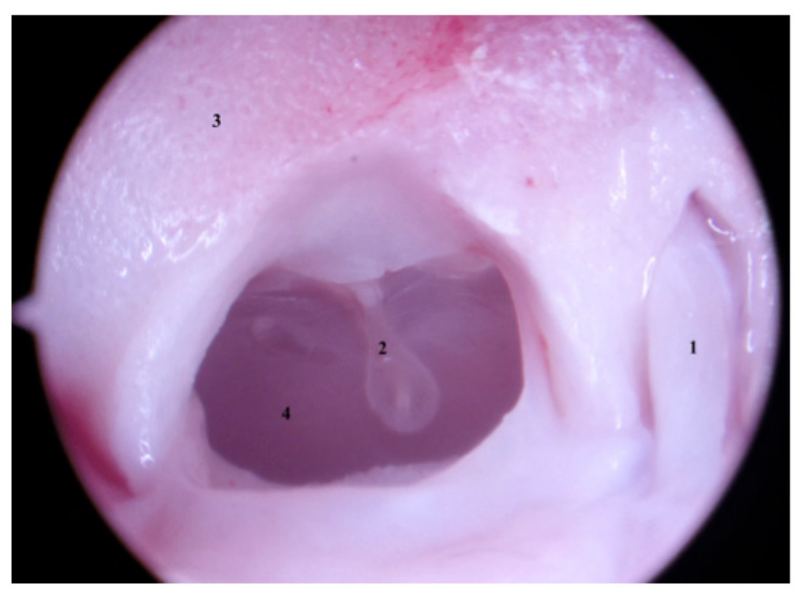

FIGURE 4 - Endoscopic view. 1 - Facial nerve; 2 - Malleus; 3 - Dorsal bula; 4 - Tympanic membrane.
The cochlea is found attached inferiorly to medial of bulla by a bony shelf. It projects its greater axis anterior and inferiorly, and round window locates in superior aspect of basal turn, whereas oval window locates superior and anterior. Posterior semicircular canal is located posterior and inferior to the cochlea, ridging in a superior direction. Lateral semicircular canal is found posterior and inferior, following a superior-anterior direction. Superior semicircular canal is located on the posterior wall of epitympanic space. In epitympanic space, incudomalear complex is easily identified. (Figures 5-8).

Inspecting external auditory canal, using the scope, malleus is observed, with relative ease. Side wall of the bulla, epitympanum and mastoid are also identified. With bone removal of the sidewall, epitympanum is accessed with exposure of incudomalear complex is gained. Posteriorly, in epitympanum, lateral and superior semicircular canals can also be located.

When guinea pig tympanic bulla is opened, cochlea is seen in its interior, with its bony cover and the ossicular chain intact, it is only possible to notice round window, because oval window is covered by the stapes. Its removal enables a better visualization (Figures 5-8).

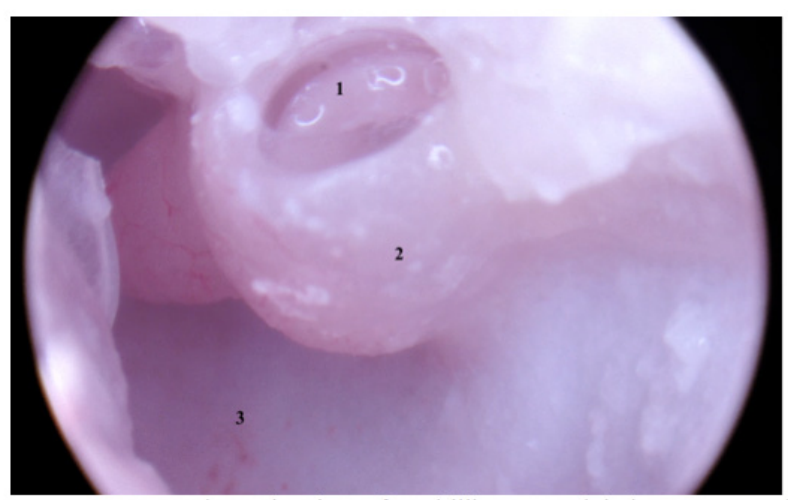

FIGURE 5 - Endoscopic view after drilling ventral bula. 1 - Round window; 2 - Cochlea; $\mathbf{3}$ - Ventral bula.

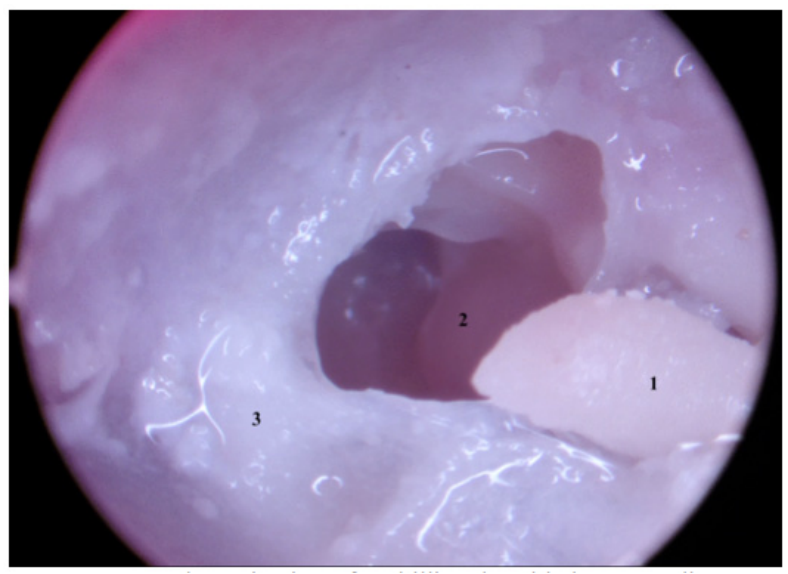

FIGURE 6 - Endoscopic view after drilling dorsal bula. 1 - Malleus; 2 Cochlea; 3 - Dorsal bula. 


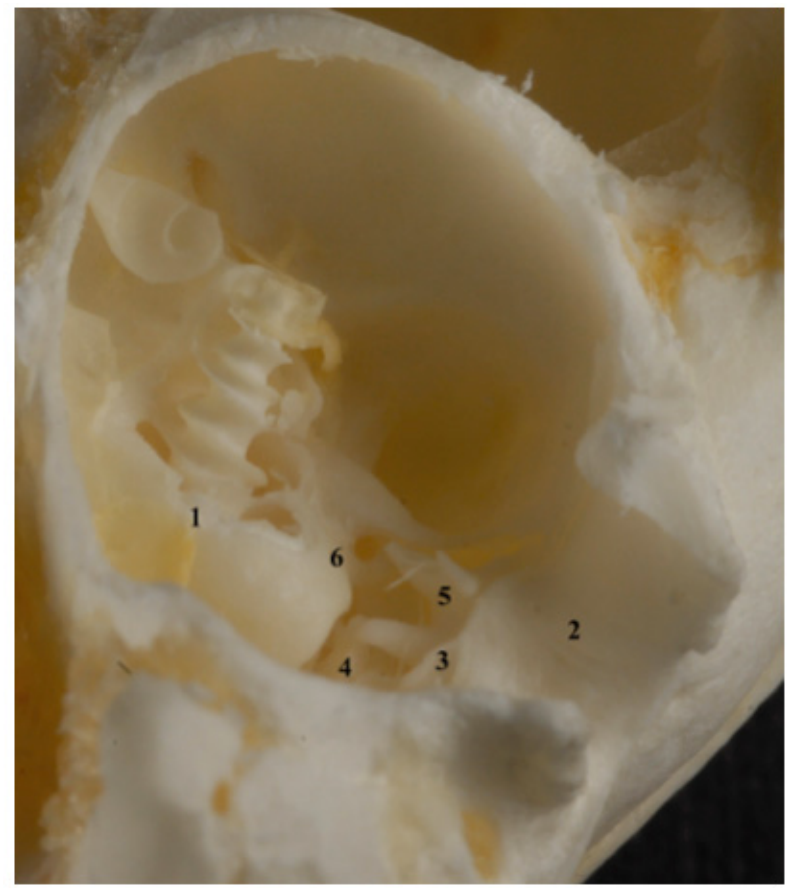

FIGURE 7 - Ventral view, oppened bula, left ear. 1 - Cochlea; 2 - External auditory canal; 3 - Incus; 4 - Stapes; 5 - Malleus; 6 - Tensor tympani canal

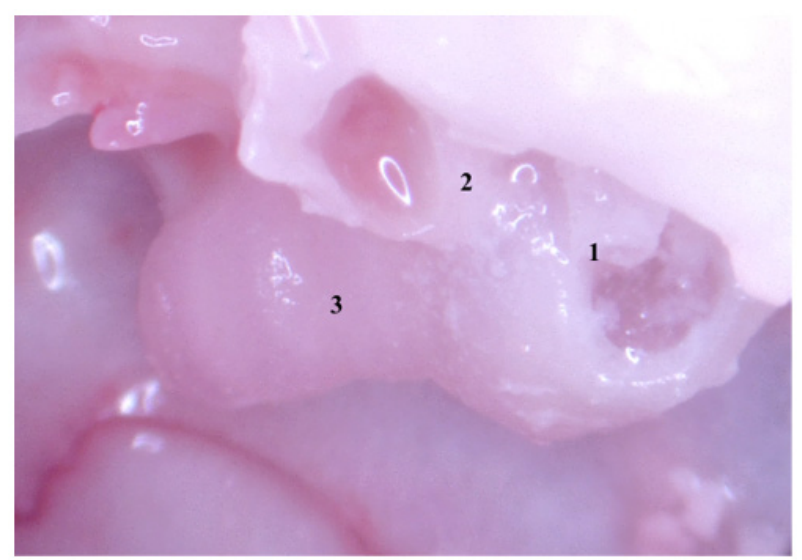

FIGURE 8 - Endoscopic view in dorsal bula 1 - Round window; 2 - Oval window; 3 - Cochlea.

\section{Discussion}

Guinea pigs are frequently used in otological research, mainly because of anatomical similarities and fine handling. Guinea pig temporal bone, cochlea and its components are similar to those of men, with few exceptions, including a compressed ossicular chain, with malleus and incus forming the incudomalear bone complex, and the stapes. The dimensions of the tympanic membrane are significantly higher in guinea pigs and devoid of pars flacida $^{2-4}$.

Traditionally, two surgical approaches are described in guinea pigs ear: "superior approach" and "inferior approach".
Both ways are described under microscopic visualization and maintain integrity of tympanic membrane, which is opportune. These approaches allow visualization of different structures: the "superior approach" leads to the round and oval windows, epitympanic space and surrounding structures, whereas the "inferior approach" leads to a better visualization of Eustachian canal and cochlea ${ }^{4-6}$. Using endoscope, we were able to identify most landmarks without the need of a cervical incision. The “endoscopic approach" offers several visualization angles and might enable the future development of new experimental models for transcanal otological surgery, minimizing incisions and trauma.

The cochlea in mainly a middle ear structure in guinea pigs, which is reported in many microscopic studies ${ }^{4-6}$, despite being functionally a component of inner ear. Human cochlea is less accessible: its location is medial to middle ear. This position represents an advantage in experimental models involving inner ear, like drug administration studies and cochlear implants. The number of cochlear spiral turns may vary among the reports ${ }^{5,6}$. Dimensions in guinea pigs are approximately 3.25 turns; however in humans, it ranges from 2.5 to 2.75 . The cochlea mostly resembles the human cochlea, if bony capsule is removed.

Surgical microscopes provide an excellent quality amplified image in a straight line and stereoscopic vision. There are however, limitations inherent to the equipment, regarding: lighting decrease, which is proportional to increases in magnification; and limitation of visual field, specially in narrow segments as the guinea pig ear. Endoscopes have traditionally played a marginal and limited role in classic ear surgery. Its main handicaps are single-handed work and lack of a stereoscopic view, which is crucial for otological surgery ${ }^{3}$. There are also concerns regarding mechanical and thermic trauma, a potentially long learning curve in order to get used to the instrument, and also space conflicts between surgical gear during the procedures. We have performed dissections using $4 \mathrm{~mm}$ scopes, $0^{\circ}$ wide angle lens, perceiving amplified images which can be modified by advancing or pulling instrument back. This dynamic feature provide, in some way, a better depth perception. We wonder that using thinner scopes (e.g. $2.7 \mathrm{~mm}$ ) and lens in different view angles (e.g. $30^{\circ}, 40^{\circ}$ ) might allow us to have improvements in dissection and approach.

Endoscopes are being increasingly used in middle ear surgery $^{3}$, but to our knowledge, this is the first description of anatomy using scopes in guinea pig ear ${ }^{5-7}$. These instruments are neat for educational and training purposes, as the endoscopes ease visualization, documentation and surgical recordings. Many human ear anatomy-based papers have been published, displaying 
advantages of endoscope usage in ear surgery, especially due to a better visualization of the structures and recesses within temporal bone spaces. Both microscope and endoscope were used in this paper during dissections, enabling comparisons and alternate switches between instruments, as there are some instances in which endoscope could be best-suited instrument when compared to the microscope, and vice-versa. Accordingly they might be complementary. For instance, in the general, topographical view of temporal bone in relation to surrounding structures of skull, microscope seems to be foremost. Alternatively, visualization of cochlea, round and oval windows and other inner ear structures is remarkably optimized using scopes. However, compared to humans, which have a wider and lengthier external ear canal, endoscopic visualization of guinea pigs ear might have a lesser contribution, hence air spaces are plainer and more obvious, indeed narrow.

\section{Conclusions}

The description of topographic anatomy allowed visualization of the position of temporal bone structures and landmarks in the skull, and its relations to external accesses may guide dissection. The structures and recesses of the middle ear were well identified and recorded by the endoscope, enabling the development of transcanal endoscopic procedures.

\section{References}

1. Asarch R, Abramson M, Litton WB. Surgical anatomy of the guinea pig ear. Ann Otol Rhinol Laryngol. 1975;84:250-5.

2. Albuquerque AAS, Rossato M, Oliveira JAA de, Hyppolito MA. Conhecimento da anatomia da orelha de cobaias e ratos e sua aplicação na pesquisa otológica básica. Braz J Otorhinolaryngol. 2009;75(1):43-9.

3. Marchioni D, Molteni G, Presutti L. Endoscopic anatomy of the middle ear. Indian J Otolaryngol Head Neck Surg. 2011;63(2):10113.

4. Aquino TJM de, Oliveira JAA de, Rossato M. Ototoxicity and otoprotection in the inner ear of guinea pigs using gentamicin and amikacin: ultrastructural and functional aspects. Rev Bras Otorrinolaringol. 2008;74(6):843-52.

5. Sanli A, Aydin S, Oztürk R. Microscopic guide to the middle ear anatomy in guinea pigs. Kulak Burun Bogaz Ihtis Derq. 2009;19(2):87-94.

6. Sehitoğlu MA, Uneri C, Celikoyar MM, Uneri A. Surgical anatomy of the guinea pig middle ear. Ear Nose Throat J. 1990;69:91-7.

7. Wysocki J. Topographical anatomy of the guinea pig temporal bone. Hear Res. 2005;199:103-10.

\section{Correspondence:}

Ektor Tsuneo Onishi

Rua Pedro de Toledo, 947

01428-010 São Paulo - SP Brasil

Tel./Fax: (55 11)5549-7041

ektor.onishi@gmail.com

${ }^{1}$ Research performed at Otolaryngology and Head and Neck Surgery Division, Federal University of Sao Paulo (UNIFESP), Brazil. 